Revista Água Viva

ISSN 1678-7471

\title{
VALE TUDO EM PEGA PEGA - O MESMO QUE SIGNIFICA DIFERENTE (EM) CENA DA LITERATURA TELENOVELÍSTICA BRASILEIRA
}

\section{VALE TUDO IN PEGA PEGA - THE SAME WHICH MEANS DIFFERENT (IN) SCENE OF THE BRAZILIAN SOAP OPERA LITERATURE}

\author{
Claudemir dos Santos Silva ${ }^{1}$ \\ Dalexon Sérgio da Silva ${ }^{2}$
}

Recebido em: 13 jan. 2020

Aceito em: 02 jun. 2020

DOI 10.26512/aguaviva.v5i2.29183

\begin{abstract}
RESUMO: Dentro do processo de criação literária, a novela trata-se de uma das várias manifestações em prosa. À vista disso, a televisão vem explorando tal componente através do núcleo artístico das telenovelas brasileiras, com instigantes possibilidades, inclusive, de trazer à tona cenas clássicas que fizeram grande sucesso e marcaram época na dramaturgia. Nesse enquadramento, pelo viés da Análise do Discurso de linha francesa, enquanto dispositivo teórico e analítico, vê-se o mobilizar da memória discursiva, que repete, refuta e transforma-se, histórica e socialmente na ação da literatura telenovelística, produzindo efeitos de memória nos telespectadores, gerando novas formulações no interdiscurso das personagens que se comportam como aquelas e trazem o repetível, "puro já dito", em outros momentos da teledramaturgia. Desse modo, este artigo pretende analisar a presença da memória discursiva e do interdiscurso na ação que o personagem Athaíde tenta fugir e reviver/refazer a cena em que Marco Aurélio "faz um gesto de mandar uma banana para o Brasil", dando visibilidade aos movimentos parafrásticos e polissêmicos que se fundam sob essas diferentes conjunturas. Focam-se como objetos de análises as novelas Vale Tudo (1988) e Pega Pega (2017), veiculadas pela TV Globo e como corpus discursivo utilizou-se duas imagens que circulam na mídia digital.
\end{abstract}

Palavras-chave: Vale Tudo. Pega Pega. Telenovela. Paráfrase. Polissemia.

\begin{abstract}
Within the process of literary creation, the soup opera is one of several manifestations in prose. In view of this, television has been exploring such a component through the artistic core of Brazilian soap operas, with thought-provoking possibilities, including bringing to light classic scenes that were highly successful and marked epoch in dramaturgy. In this context, through the approach of Discourse Analysis of the French line, as a theoretical and analytical device, we see the mobilization of discursive memory, which repeats, refutes and

\footnotetext{
1 Mestre e Doutorando do Curso em Ciências da Linguagem pela Universidade Católica de Pernambuco (UNICAP), bolsista FACEPE. Recife, Pernambuco, Brasil. E-mail: claudemirsilva711@ gmail.com

${ }^{2}$ Pós-doutorando e Doutor em Ciências da Linguagem pela Universidade Católica de Pernambuco (UNICAP) em Programa de Doutorado-sanduíche no Exterior - PDSE - CAPES, pela Universidade de Lisboa/Universidade Aberta de Lisboa. Membro do Centro de Literaturas e Culturas Lusófonas e Europeias da Faculdade de Letras da Universidade de Lisboa - Portugal. E-mail: dalexon@uol.com.br
} 
transforms itself, historically and socially, into the action of telenovelist literature, producing memory effects. In the viewers, generating new formulations in the interdiscourse of the characters who behave like those and bring the repeatable, "pure already said", in other moments of the teledramaturgy. Thus, this article aims to analyze the presence of discursive memory and interdiscourse in the action that the character Athaíde tries to escape and revive/redo the scene in which Marco Aurélio "makes a gesture of flipping the finger to Brazil", giving visibility to the paraphrastic and polysemic movements that merge under these different junctures. Focus on as objects of analysis are the soap operas Vale Tudo (1988) and Pega Pega (2017), broadcasted by TV Globo and as a discursive corpus, two images that circulate in digital media were used.

Keywords: Vale Tudo. Pega Pega. Soap opera. Paraphrase. Polysemy.

\section{INTRODUÇÃO}

A televisão ocupa um papel preponderante na formação do discurso dos sujeitos, uma vez que está presente em quase todos os lares, por isso, tem um lugar significativo na vida do ser humano. Companheira inseparável de muitos, tratando-se, portanto, de "diversão para uns, trabalho para outros e instrumento de formação de pensamentos, assim é a televisão que mesmo na era da tecnologia, onde a conectividade está nos celulares, tabletes e notebooks, a TV ainda continua sendo a preferida de muitos" (HOLANDA, 2014, p. 15). Nesse ínterim, nos anos 1950, a televisão ${ }^{3}$ era operada como uma extensão do rádio, de quem herdou os padrões de produção, programação e gerência, envolvidos num modelo de uso privado e exploração comercial.

Assim, a TV veio se modificando ao longo dos anos, através das programações diversas como: telejornais, novelas, programas de auditório, dentre outros. Entre as inovações da programação televisiva, uma das atrações que mais se destacam são as telenovelas, com mais de meio século de existências, ou seja, "a novela já era embrionariamente cultivada na Antiguidade greco-latina".

Logo, a novela pode ser entendida conforme os parâmetros em que dá-nos movimento, uma vez que trata de misturar "o relato historicamente verídico ao fantástico ou mítico e apelando para a poesia ou mesmo para digressões oratórias e retóricas”, daí, a ficção clássica

\footnotetext{
${ }^{3}$ Em 18 de setembro de 1950, às 17h, São Paulo, ocorreu a primeira transmissão de imagens no Brasil pela TV Tupi-Difusora uma emissora dos Diários Associados de Assis Chateaubriand. Sendo o primeiro país da América Latina a ter uma faixa de frequência reservada para as transmissões de televisão e o sexto no mundo, perdendo apenas, para Inglaterra, Estados Unidos, França, Alemanha e Holanda. O termo "Televisão" é muito amplo e se aplica a uma gama imensa de possibilidades de produção, distribuição e consumo de imagens e sons eletrônicos (HOLANDA, 2014).
} 
serviu de berço não só à novela propriamente dita como a outras modalidades literárias em voga na Idade Média (MOISÉS, 1985, p. 55).

Consolidando-se, assim, a ponto de ser o maior produto de exportação da televisão brasileira, inclusive, sustentando-a. Em vista disso, historicamente, de acordo com Silva (2013), esta narrativa tem sua origem fortemente calcada no gênero melodramático ${ }^{4}$, de modo que, para chegar ao que se tornou atualmente, percorreu uma trajetória que perpassou por diversos outros formatos como o folhetim, a soap-opera e a radionovela. Tendo em vista toda essa trajetória cultural, a literatura telenovelística aproxima-se mais do formato folhetinesco, por ser elaborada na perspectiva do próximo capítulo, um tipo de gancho, sempre em direção a um desfecho da história (ORTIZ et al, 1991), então, distinguindo-se da soap-opera por sua duração e ser exibida em horário nobre. Nesse ponto, “sua difusão é simultânea à produção, ou seja, é veiculada ao mesmo tempo em que é escrita, gravada e editada, o que certamente suscita diversas formas de interlocução entre produção e recepção, ainda que desiguais" (SILVA, 2013, p.08).

Nessa conjuntura sócio-histórica, circunscrevem-se as novelas "Vale Tudo" (1988) e "Pega Pega" (2017), sobre a primeira, o site rdl.com. br, no dia 16 de maio de 2018, publicou a seguinte matéria: "Como não amar "Vale Tudo"? 10 motivos para curtir a reprise desse clássico que faz 30 anos". Observa-se que, à época, a reprise desse folhetim, dá-se em meio à celebração das três décadas de sua exibição original, pois, trata-se de um clássico da TV brasileira, com uma genialidade ímpar! Considerando tramas, diálogos, elenco, produção e bastidores.

Além disso, o enredo da telenovela Vale Tudo propunha um debate sobre ética a partir do questionamento: “vale a pena ser honesto no Brasil de hoje?". Tal questão segue inquietando a mente dos brasileiros. E, ao que parece, está longe de uma resposta definitiva, uma vez que a corrupção, das pequenas às grandes, está entranhada no dia-a-dia, tal qual no caráter de muitos personagens da literatura telenovelística, daí, poder-se observar esta junção de realidade e ficção que é o primeiro passo para entender porque o enredo da novela Vale Tudo é tão pertinente.

Com relação à segunda telenovela, o site época. globo.com, no dia 7 de junho de 2017 , traz a seguinte publicação: "Estreia de Pega Pega quebra recorde de audiência às $7 \mathrm{~h}$ ". $\mathrm{Na}$ sequência do capítulo, viu-se uma perseguição estrelada por Vanessa Giácomo, a policial

\footnotetext{
${ }^{4}$ - O vocábulo melodrama nasceu na Itália, no século XVII e designava um drama inteiramente cantado. O termo só foi aparecer na França no século XVIII, durante a querela entre franceses e italianos (THOMASSEAU, 2005, p.16).
} 
Antônia, e o romance de Luiza e Eric, vividos por Camila Queiroz e Mateus Solano. Diante disso, à época, fazendo com que o ibope da faixa das $7 \mathrm{~h}$, no capítulo de estreia da trama, naquela terça-feira (06/06/2017), alcançasse uma marca que registrou 29 pontos de média, registro esse que não se via, desde a estreia de "Cheias de charme", em 2012 e disparou entre os tópicos mais comentados nas redes sociais.

À vista de toda essa narrativa, este artigo pretende analisar a presença da memória discursiva e do interdiscurso na ação em que o personagem Athaíde tenta fugir e reviver/refazer a cena em que Marco Aurélio "faz um gesto de mandar uma banana para o Brasil" 5, dando visibilidade aos movimentos parafrásticos e polissêmicos que se fundam sob essas diferentes conjunturas.

Para tanto, utiliza-se no corpus discursivo, a imagem que circula na mídia digital, na qual o personagem Athaíde (Reginaldo Faria), em "Pega Pega" (2017), para evitar que Lígia (Ângela Vieira) seja presa por assassinato, tenta fugir com ela em um jatinho particular. $\mathrm{O}$ mesmo motivo que levou seu antigo vilão, Marco Aurélio, a sumir com a mulher, Leila (Cássia Kiss), a assassina de Odete Roitman (Beatriz Segal), mandando uma banana para o Brasil. Com isso, Claudia Souto, autora da trama das sete, faz uma referência à "Vale tudo", exibida na TV há 30 anos. Nesse sentido, tendo em vista o que Pêcheux $(1969,1975)$ denomina de movimentos parafrásticos e polissêmicos, pretende-se, então, ver o funcionamento, nessas cenas de novelas analisadas, dessa relação sempre constitutiva da paráfrase e polissemia.

Sendo assim, este artigo está distribuído, de forma a apresentar o trabalho ao leitor, nas considerações iniciais, justificando-o e marcando problematizações e objetivos. O item 1 pretende situar, brevemente, algumas considerações históricas sobre a constituição da televisão no Brasil e da literatura telenovelística. O item 2 discute a teoria e procedimento analítico, suporte deste trabalho, a Análise do Discurso de linha francesa (AD), tal qual delineada na França por Michel Pêcheux, reterritorializada no Brasil por Orlandi e continuada por estudiosos. Em seguida, pretende-se evidenciar o percurso metodológico do trabalho, para, finalmente, no item 4, trazer à discussão o corpus discursivo dos sujeitos personagens de novelas em estudo, focando no aspecto da memória discursiva, da paráfrase e polissemia. Por último, haverá o fechamento do trabalho, com as considerações finais.

\footnotetext{
5 - Dada a frequência do uso sem cerimônia do bananento gesto, parece que a maioria das pessoas ignora que ele significa bem mais do que desdém e desprezo. Bem mais, gesto aparentemente inventado pelos americanos para mimosear motoristas irritados e outros desafetos eventuais. Herdando-se de Portugal, onde é ou era comum, o dar bananas, obsceno pelo menos na origem (CHUMBOGORDO. com. br., 2020).
} 


\section{A constituição da televisão no Brasil e da literatura telenovelística}

A televisão se caracteriza, conforme Balogh (2002) pela sua extraordinária capacidade de absorção de outras linguagens e textos, bem como por sua enorme voracidade ao fazê-lo, posto que permanece praticamente o dia todo e todos os dias do ano no ar. A explicação para tal fenômeno está na gênese da própria mídia, onde surgiu como um apanhado de conquistas prévias no campo da literatura, das artes plásticas, do rádio, do folhetim, do cinema.

Nesse contexto, dentre as manifestações literárias no Brasil, escolheu-se, neste artigo, a literatura novelística, porque se trata de uma criação que tem atraído a atenção dos telespectadores. A telenovela ${ }^{6}$ teve o seu surgimento, quase que ao mesmo tempo da inauguração da televisão em 1950, mas sua veiculação diária só iniciou em 1963, onde nenhum meio de comunicação goza de tanta importância no país quanto a TV, meio que a acolhe e dissemina seu principal produto.

Nesse enquadramento, Moisés (1985 p. 55) explica que a palavra novela remonta possivelmente do italiano novella, que, por sua vez, teria origem na forma latina novella, de novellus, a, um, adjetivo diminutivo originário de novus, a, um. Do sentido de "novo", "incipiente", a palavra derivou para "embaraçado", "enredado". De maneira que:

Substantivada e adquirindo denotação especial, durante a idade média acabou significando "enredo", "entrecho", e daí "narrativa enovelada", "trançada". Com tal sentido, a palavra passou para outras línguas. Em Português, além da acepção popular de novilha, a palavra circula ainda como sinônimo de "engano", "embuste", "mentira", e pode significar vulgarmente qualquer história longa e sentimentalona, sobretudo quando transmitida pela rádio e pela televisão. Literariamente, como se viu, o termo por vezes de modo defeituoso, pois designaria, ao ver de alguns, as narrativas que encerram 100 e 200 páginas (MOISÉS, 1985, p. 55).

Portanto, ao longo do tempo nota-se que tal nomenclatura vai circulando em diversas línguas e no Português, como já afirmou Moisés (1985, p. 55) “pode significar qualquer história longa e sentimentalona, sobretudo quando transmitida pela rádio e pela televisão". Dessa forma,

\footnotetext{
6 - O termo é de origem castelhana, particularmente do espanhol falado em Cuba, país precursor desse gênero audiovisual que foi inspirado nas radionovelas. $\mathrm{O}$ vocábulo é fruto da fusão das palavras: tele (de televisão) e novela, que em espanhol é o mesmo que romance em português (SILVA, 2013).
} 
a literatura telenovelística brasileira é a que, de certa maneira, melhor propaga uma metamorfose de textos plurilinguísticos e multifacetados em suas tramas, pois é/faz parte do produto televisivo, e sua estrutura é passível de absorver outros textos em suas mais diversas relações memoráveis e interdiscursivas, onde muitas vezes, a paráfrase, "matriz do sentido" em sua produtividade, dá vez à polissemia "fonte do sentido", que se desloca para o "mesmo" e aponta para a ruptura, com criatividade.

No rol de folhetins brasileiros, como esquecer-se de cenas que marcaram época e tornaram-se grandes clássicos da dramaturgia, tais como: Carlão sendo baleado nas obras do metrô $(1975 ; 1998)$, a volta triunfal de Clara ao som de Blaze of glory, sob o olhar pasmado dos seus inimigos (2017), Julia Mattos dançando loucamente na discoteca (1978), a viúva Porcina indecisa entre ficar com Sinhozinho Malta ou partir com Roque (1985), as brigas épicas entre Nina e Carminha e as suas reviravoltas (2012), a megera Laurinha Figueroa, jogando-se do prédio da Sucata (1990), Nazaré empurrando pessoas da escada e, no final, jogando-se fantasticamente da ponte de uma hidroelétrica (2004), Maria Clara dando uma surra inesquecível na vilã Laura (2004) e o momento em que Marco Aurélio (1988), fugiu com Leila, mandando uma banana para o Brasil?

Nessa diretriz, é certo que tais atos estão como um registro histórico e afetivo na memória discursiva e social dos sujeitos/telespectadores. Pois, sabidamente, no universo da teledramaturgia, onde há puro "encantamento", tudo é possível. Daí, explica-se a paixão dos brasileiros por esse gênero audiovisual, que, apesar disso, é um produto constituído por uma fusão de drama, romance e violência de uma forma bem peculiar aos telespectadores. Atrelado a isso, trata-se de uma unidade de significação de grande oralidade, comportando diversas formas de expressão artística como: texto, música, dança e imagem (SILVA, 2013), consequentemente, revela-se enquanto fenômeno histórico, social e afetivo do povo, ou seja, são verdadeiros patrimônios do inconsciente coletivo do país.

\subsection{As telenovelas - Vale Tudo e Pega Pega: entretecendo discursos}

Em 1951, Walter Forster, diretor, autor e protagonista, lançou a telenovela "Sua vida me pertence” (TV Tupi, 1951), respaldado na estrutura radiofônica de apresentar dramaturgia. Inicialmente, a literatura telenovelística era veiculada com quinze capítulos e exibida duas vezes por semana, o que remete à forte ligação com o folhetim do século XIX e com todo o arcabouço da radionovela. Sendo assim, foi a partir dessa experiência e também do sucesso que 
gozava, que tal gênero foi transformado em um produto de veiculação diária. A trajetória da telenovela brasileira também se dinamizou quanto a seu modo de narrar. Para tanto, a partir da década de 1970, foi abandonado o caráter folhetinesco (a exemplo dos dramalhões mexicanos), mudando sua lógica de temáticas dos príncipes, castelos, etc. indo ao encontro de temáticas mais realísticas, aproximando-se, então, de temas do cotidiano nacional.

Nesse entrecho, a palavra novela deve ter entrado para a Língua Portuguesa graças ao influxo das novelle italianas, vocábulo que ainda podia revestir o sentido de "conto", aliás, sua fôrma assim, sobretudo naqueles confusos anos do crepúsculo da Idade Média. Durante algum tempo, foi empregada no sentido pejorativo de "narrativa fabulosa, fantástica, inverossímil". "Só no Romantismo, mercê de profunda metamorfose cultural, desencadeada em toda parte, é que a palavra novela ganhou a significação literária que possui atualmente” (MOISÉS, 1985, p. 55, grifos nossos).

Nessa dinâmica, o enredo das telenovelas se desenvolve através de diálogos apresentados por personagens centrados, principalmente, em núcleos familiares. Logo, aquilo que aconteceu ou está por acontecer é anunciado aos telespectadores por meio de falas, de imagens. "As ações, por mais visuais que sejam, deixam-se acompanhar por trilhas musicais descritivas e toda uma ambientação sonora" (LIMA, 2000, p. 134).

Em vista disso, essa narrativa pode ser entendida como um produto da indústria cultural, uma história de ficção desenvolvida para apresentação na televisão, sendo estruturados em capítulos que costumam ter em média 55 minutos diários de duração, exibidos de segunda a sábado, durando aproximadamente, oito meses. Só na grade de programação da Rede Globo, por exemplo, são exibidas cinco telenovelas entre 14 e $21 \mathrm{~h}$, além da novela das onze, que é produzida de acordo com os interesses da emissora. De forma geral, o sucesso ou não tem ocorrido, "pela forma como as novelas são construídas, incorporando conteúdos das narrativas tradicionais, da dramaturgia, do cinema, sem esquecer, entretanto, da perfeita ambiguidade traçada com o real" (AMOROSO; MONTUORI, 2017, s/p).

Nesse contexto, em 1988, estreou Vale Tudo, uma das grandes novelas já produzidas pela TV brasileira, tendo como temáticas: a questão da corrupção e falta de ética. A trama foi escrita pela trinca de beldades: Gilberto Braga, Aguinaldo Silva e Leonor Bassères, com a direção de Dennis Carvalho e Ricardo Waddington. Os autores centraram a discussão do folhetim sobre honestidade e desonestidade no antagonismo entre mãe e filha. De maneira que, a íntegra Raquel Accioli (Regina Duarte) é o oposto da filha, Maria de Fátima (Gloria Pires), jovem inescrupulosa e com horror à pobreza. Logo nos primeiros capítulos, vende a única 
propriedade da família, no Paraná, e foge com o dinheiro para o Rio de Janeiro, objetivando se tornar modelo (MEMÓRIA GLOBO, 2018). Na galeria de personagens ricos e inesquecíveis, encontra-se uma das maiores megeras da dramaturgia, Odete Roitman (Beatriz Segall), que acabou assassinada, gerando um grande mistério na trama e rendeu um dos "quem matou Odete Roitman?" mais emblemáticos da TV. O Brasil "parou" para saber "o assassino" da vilã, e para surpresa de muitos, uma personagem que quase ninguém esperava: Leila (Cassia Kiss), que atira pensando se tratar de Maria de Fátima, amante de seu marido, o mau-caráter Marco Aurélio (Reginaldo Faria).

Já Pega Pega (2017), novela das sete, escrita por Claudia Souto e com direção artística de Luiz Henrique Rios, teve seu enredo centrado numa comédia romântica policial, onde o ponto de partida é um roubo milionário ao "Hotel Carioca Palace". A trama foi ambientada entre os bairros de Copacabana e Tijuca, e propôs uma reflexão sobre a relação de todos com o dinheiro. De maneira que, o romance dos protagonistas Luíza (Camila Queiroz) e Eric (Mateus Solano) fica por um triz a partir da compra do hotel pelo empresário, tal venda é feita sem o consentimento da neta, pelo avô, Pedrinho Guimarães (Marcos Caruso).

O bon vivant só não contava que sua ideia de sumir do país daria errado, porque no momento da transação ocorre um plano arquitetado por Malagueta (Marcelo Serrado), Júlio (Thiago Martins), Sandra Helena (Nanda Costa) e Agnaldo (João Baldasserini), que levam/subtraem do cofre em pleno baile de gala de Luíza, os seus 40 milhões de dólares. Restando, portanto, à policial Antônia (Vanessa Giácomo) tentar desvendar os crimes e fazer com que todos, inclusive, o casal, Lígia (Ângela Vieira), pelo atentado que matou Mirella (Marina Rigueira) e Athaíde (Reginaldo Faria), ex-desembargador acusado de venda de sentenças judiciais, paguem por seus delitos (GSHOW, 2018).

\section{Sujeito, memória discursiva, paráfrase e polissemia na Análise do Discurso de linha francesa}

Na perspectiva da $\mathrm{AD}$, o discurso não é fechado em si mesmo e nem é domínio exclusivo do locutor, pois "aquilo que se diz, significa em relação ao que não se diz, ao lugar social do qual se diz, para quem se diz, em relação a outros discursos" (CAZARIN, 2001, p. 143-144). Portanto, a $\mathrm{AD}$, como seu próprio nome indica, não trata da língua, não trata da gramática, embora todas essas coisas lhe interessem. "Ela trata do discurso. E a palavra discurso, etimologicamente, tem em si a ideia e curso, de percurso, de correr por, de movimento" 
(ORLANDI, 2013, p. 15). Desde a gênese da Teoria do Discurso, Pêcheux (1969; 1975) entende que são as lutas de classes que movem a sociedade e os discursos.

Embora existam outras áreas dos estudos da linguagem que foquem na compreensão dos diversos discursos circulantes na sociedade, é a partir de Pêcheux (1993 [1969]), que o discurso passa a ser concebido como efeitos de sentido entre locutores. Desse modo, "o discurso é um fenômeno intermediário entre a língua (geral) e a fala (individual), nasce em outros discursos, isto é, a partir de formações discursivas que, por sua vez, integram uma ou mais formações ideológicas” (ORLANDI, 2011, p. 157-158).

Já os sentidos, por sua vez, "não estão nas palavras, que mudam de sentido segundo as posições sociais daqueles que a empregam”, daí, "o sujeito ao produzir sentidos diz mais sobre si do que sobre aquilo que ele diz" (SOARES, 2017, p. 35). Na verdade, o discurso é/será determinado pela posição-sujeito, dada em uma posição ideológica e sócio histórica também (ORLANDI, 2013, p. 43), porque conforme Althusser (1985, p. 99), “o lugar desse sujeito já foi dado, ele já se inscreveu, há, portanto, uma predeterminação ideológica”.

Na AD, de acordo com Maliska (2017, p. 50), "toda a problemática do sentido, ou melhor, de seus efeitos e defeitos, se dá através de uma premissa que a linguagem não é um código a ser decifrado pelo receptor que a receberia cifrada pelo emissor”, logo, não devemos entender a linguagem como comunicação, mensagem, código, enfim, nada disso. "Desse modo, o discurso e a linguagem estão abertos à polissemia, a uma produção de sentido outra, inesperada [...]" (MALISKA, 2017, p. 51).

Nesse espaço, o discurso possibilita formas de conhecimento em seu conjunto (ORLANDI, 2013) e na prática, concebe um acontecimento, evidenciando, então, "efeito de sentidos entre locutores" (PÊCHEUX, 1997), uma vez que propõe a noção de funcionamento, isto é, a relação existente entre condições materiais de base (língua) e processo (discurso).

Nesse direcionamento, a partir dos discursos de Leandro Ferreira (2005, p. 73), é preciso salientar que a concepção de linguagem que norteia a AD é a da psicanálise, onde o sujeito não é consciente e nem tem controle sobre o que diz, isto é, ele (o sujeito) é clivado, assujeitado, desejante. Tal categoria, introduzida na $\mathrm{AD}$, é pensada a partir de formulações de Lacan, ganhando estatuto próprio. No entanto, "não nos apropriamos do sujeito da psicanálise, mas levamos em consideração o sujeito inconsciente, descentrado, não-uno, onde a incompletude é muito marcante no sujeito" (LEANDRO FERREIRA, 2005, p. 73). 
Dessa maneira, "na Psicanálise, a hipótese do inconsciente produz uma divisão do sujeito, que fica seccionado entre sua intencionalidade consciente e seu dizer inconsciente, [...] entre o que se diz e o que se pensa ou se almeja dizer" (MALISKA, 2017, p. 70). Ao mesmo tempo, é sujeito da ideologia, tal como teoriza Althusser (1991), afirmando que esse processo é decorrente do assujeitamento ideológico, onde se dá a ilusão do sujeito, no sentido de que o assujeitamento, ligado à ambiguidade do termo sujeito, "exprime bem esta "fixação" de liberdade e de vontade do sujeito: o indivíduo é determinado, mas para agir, ele deve ter a ilusão de ser livre mesmo quando se submete" (HAROCHE, 1992, p. 178).

Dessa forma, compreende-se que os dizeres, como bem pontua Orlandi (2013), não são apenas mensagens a serem decodificadas, mas efeitos de sentido que são produzidos em condições determinadas. Essas condições de produção do discurso "compreendem fundamentalmente os sujeitos e a situação" (ORLANDI, 2013, p. 30-31). Em toda situação de linguagem, o sujeito e a situação, contam fundamentalmente para a AD. Mas esse sujeito e tal situação são redefinidos discursivamente como partes das condições de produção do discurso.

Diante dessas situações de linguagem, diz-se que na Análise do Discurso de linha francesa não se pode deixar de relacionar o discurso com suas condições de produção em sua exterioridade contitutiva (ORLANDI, 2015). De tal forma que, conforme Borges (2017), “o sujeito é consequência das discursivizações em torno dele, nas $\mathrm{CP}$ em que se encontra. Ele é interpelado e funciona como efeito e como materialização das interpelações constitutivas da memória discursiva" (BORGES, 2017, p.134). À vista disso, neste artigo, o papel da memória, observada e compreendida à luz da perspectiva da $\mathrm{AD}$ é defendido por Pêcheux, destacando que:

\footnotetext{
A memória seria aquilo que, face a um texto que surge como acontecimento a ler, vem restabelecer os "implícitos" (quer dizer, mais tecnicamente, os préconstruídos, elementos citados e relatados, discursos-transversos, etc.) de que sua leitura necessita: a condição do legível em relação ao próprio legível (PÊCHEUX, 2010, p. 52).
}

Em virtude disso, a memória do dizer possibilita a materialização de discursos que se processam mediante o contexto sócio histórico em que os sujeitos estão inscritos, portanto, retomando dizeres outros, para então, reformular e restabelecer discursos num complexo jogo ideológico. Nesse cenário, o interdiscurso é tratado como a memória, que por sua vez, pode ser definido por Pêcheux $(1969 ; 1975)$, como aquilo que fala antes, em outro lugar, de modo 
independente e diferentemente. Isso posto, para Pêcheux $(2010 ; 1984)$ todo discurso se constitui a partir de uma memória e do esquecimento de outro.

\section{Aspectos metodológicos}

Para a realização desse trabalho, foram feitos dois recortes discursivos, visando à análise do modo como se apresentam a paráfrase e a polissemia entre duas cenas finais de novelas que foram recordes de público, respectivamente, Vale tudo (1988) e Pega Pega (2017). Tais imagens foram extraídas dos sítios: memoriaglobo.com (recorte/cena 1) e gshow.com (recorte/cena 2).

A partir disso, foram feitos dois prints por meio de um smartphone e também realizada a descrição da fala dos personagens na cena da novela Pega Pega, o que não foi feito o mesmo em Vale Tudo, porque nesta novela a cena final se resume apenas ao gestual do personagem Marco Aurélio em dar uma banana para o Brasil. Logo, têm-se uma cena apenas gestual e outra cena verbo-gestual, por meio das expressões dos rostos de decepção dos personagens ao serem presos, por exemplo.

Nesse sentido, o trabalho de análise é iniciado pela configuração do corpus, “delineando-se seus limites, fazendo recortes, retomando-se conceitos e noções que demandam um ir-e-vir constante entre teoria, consulta ao corpus e análise. Esse procedimento dá-se ao longo de todo o trabalho" (ORLANDI, 2013, p. 66).

A seguir, procede-se à análise da cena na qual o personagem Athaíde, na novela Pega Pega (2017), tenta fugir e reviver/refazer a cena em que Marco Aurélio Vale tudo (1988) "faz um gesto de mandar uma banana para o Brasil", dando visibilidade aos movimentos parafrásticos e polissêmicos que se fundam sob essas diferentes conjunturas. 
4. Um gesto teórico-analítico sobre Vale Tudo em Pega Pega

Recorte 1 (cena 1)

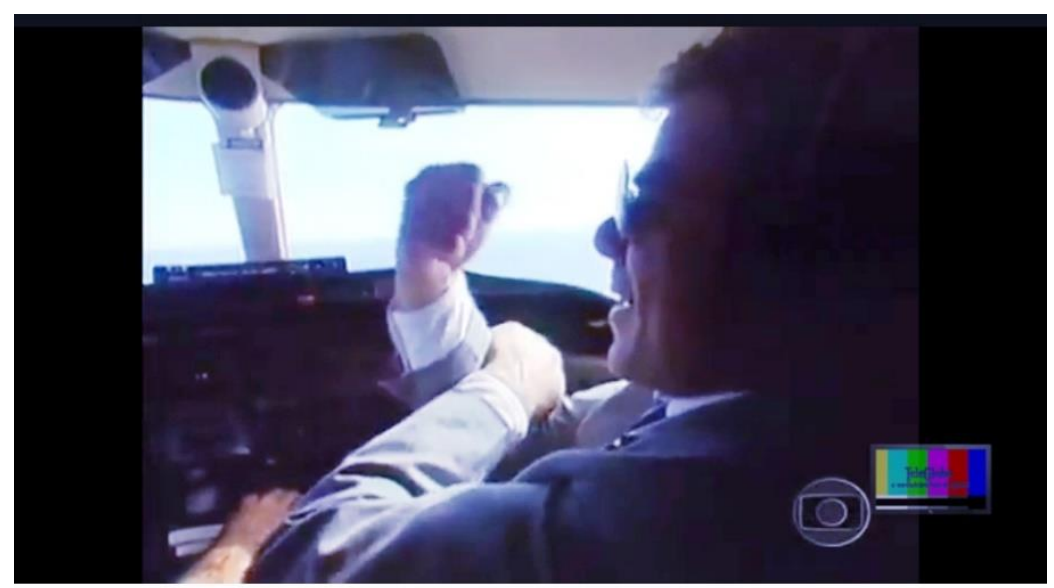

Vale Tudo: Marco Aurélio dá banana para o Brasil

TeleGlobo

Disponível em: <http://memoriaglobo.globo.com/programas/entretenimento/novelas/vale-tudo/tramaprincipal.htm>Acesso em: 07 jan. 2020

\section{Recorte 2 (cena 2)}

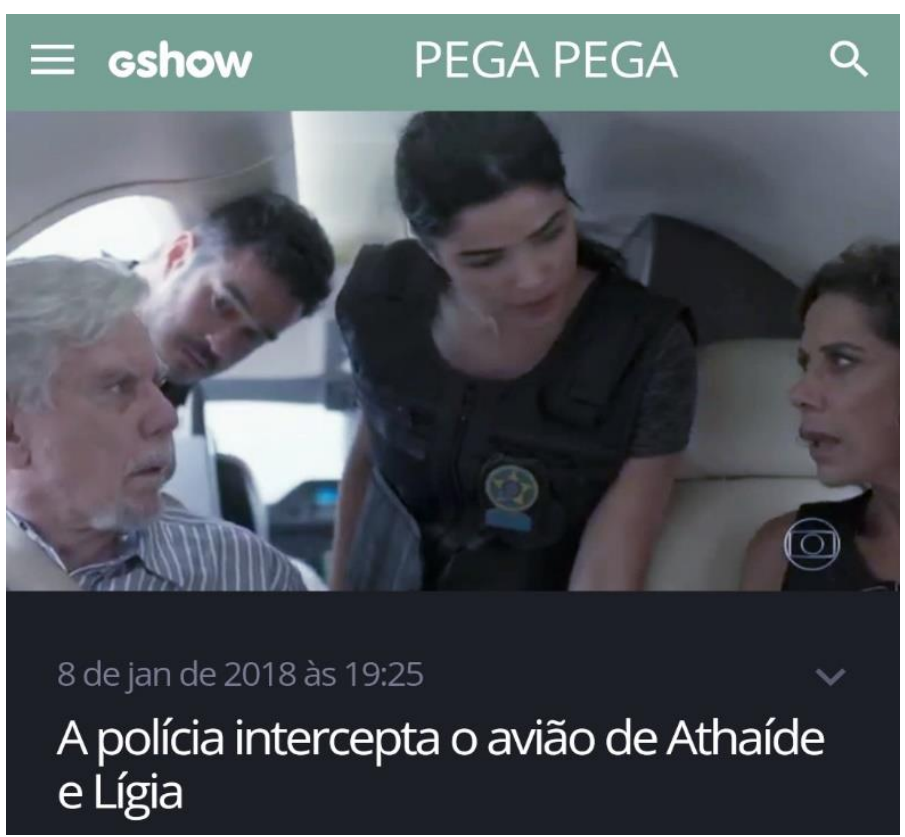




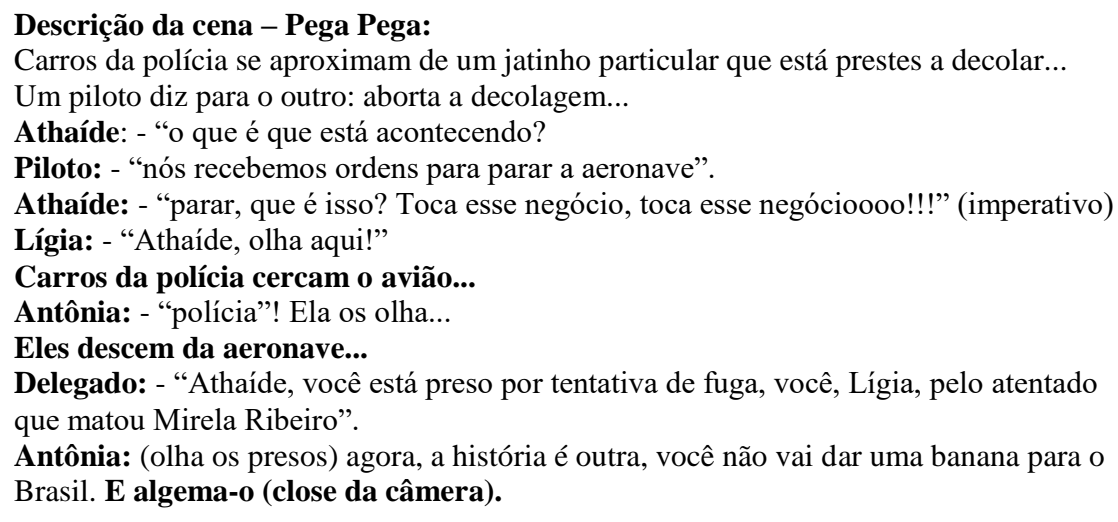

Disponível em: 〈http://gshow.globo.com/novelas/pega-pega/capitulo/2018/01/08/\#video-6407430〉. Acesso em: 07 jan. 2020.

Em 08 de janeiro de 2018, na exibição do último capítulo de Pega Pega, a autora, Cláudia Souto, trouxe um presente para os noveleiros de plantão (GSHOW, 2018). Numa cena cheia de adrenalina, o personagem Athaíde no recorte 2 (cena) 2 tenta fugir do Brasil. Esse acontecimento relembrou outro momento marcante da dramaturgia, em Vale Tudo (1988), quando o empresário, também corrupto, Marco Aurélio no recorte 1 (cena) 1, foge do Brasil sem ser punido.

Diante do que foi dito, anteriormente, e à vista das sequências discursivo-imagéticas, nos recortes/cenas 1 e 2, observa-se as personagens, reverberando o mesmo (ontem, no recorte 1) que se transforma e significa diferente (hoje, no recorte 2). Com isso, compreendemos que a língua é condição de possibilidade discursiva e está interligada ao funcionamento discursivo, "atividade estruturante de um discurso determinado, por um falante determinado, para um locutor determinado, com finalidades específicas" (ORLANDI, 2011, p. 125).

De início, é pertinente pontuar que o recorte 1 (cena) 1 e o recorte 2 (cena 2) funcionam como um texto, numa relação de composição entre a linguagem verbal e não-verbal, promovendo um jogo de incompletudes, pois, de acordo com Lagazzi (2009), os efeitos de sentido possíveis a partir da materialidade verbal estão imbricados aos efeitos produzidos a partir do não-verbal, ou seja, do discurso imagético, em uma relação de composição.

Nessa concatenação, faz-se necessário admitir-se, também, o papel exercido pela memória, assim, Pêcheux (2010) esclarece que a memória deve ser entendida não no sentido psicologista da "memória individual", mas no sentido "da memória social", que atua no interior de uma Formação Discursiva (FD) em uma relação de proximidade com o interdiscurso, visto 
que é a FD que "determina o que pode e deve ser dito" (PÊCHEUX, 1997, p. 160) no processo discursivo.

É desse modo que a cena final da novela Vale Tudo se inscreve na cena final da novela Pega Pega, numa memória atual para (d)enunciar na exterioridade constitutiva, por meio das marcas da historicidade. É ainda desse modo que essas duas cenas se mostram como materialidades discursivas. Dito de outro modo, essas imagens, aqui analisadas das novelas, possuem uma forma material, que enunciam e denunciam na exterioridade, a corrupção.

É interessante analisar que ambas as cenas das novelas Vale Tudo e Pega Pega (recorte 1 e recorte 2), promovem, por meio da paráfrase e da polissemia, uma tentativa de silenciamento. Se em Vale Tudo, a cena se mostra, sem a presença do texto verbal e sim, por meio de um gesto de dar uma banana mobilizado pelo personagem/vilão Marco Aurélio, na novela Pega Pega o elemento verbal se faz presente, contudo, ambas marcam a presença do silenciamento, da censura (ORLANDI, 2007).

Nesse entremeio, a AD, através da compreensão de discurso, possibilita formas de conhecimento em seu conjunto (ORLANDI, 2013) e na prática, concebe um acontecimento, evidenciando, então, "efeito de sentido entre locutores" (PÊCHEUX, 1990), uma vez que propõe a noção de funcionamento, isto é, a relação existente entre condições materiais de base (língua) e processo (discurso). Nessa interligação, consideramos a paráfrase e a polissemia, respectivamente, o mesmo e o diferente, como matriz e fonte de sentido, sendo os dois grandes processos da linguagem (ORLANDI, 2011).

Acerca desse silenciamento, censura, pode-se observar que o gesto de dar banana para $o$ Brasil ofertado pelo personagem Marco Aurélio, na novela Vale Tudo, promove o silenciamento de que no Brasil existe a justiça e de que alguém que cometa crime seja punido. A cena (recorte 1) faz ressoar ecos da memória discursiva que sagra o Brasil com a paráfrase que lhe alcunha como "O País da Impunidade e dos Absurdos". Já os efeitos de sentido provocados pelo final da novela Pega Pega (recorte 2) censura tal peráfrase e marca o lugar do Brasil como o, agora, "diferente", o Brasil que pune a quem comete crimes.

Se no recorte discursivo 1 , toda a cena gira em torno desse gesto simbólico do personagem corrupto dar banana para o Brasil e livrar-se impune, no recorte discursivo 2, conforme a descrição da cena aqui feita, é possível analisar que há a presença dos enunciados dos sujeitos bem marcados, com efeitos de sentido de ênfase, interdição e de prevalecimento da 
justiça, bem representada por meio de um dos aparelhos ideológicos do Estado, a polícia, como bem observa Althusser (1985), sobre o atuar dos AIE.

Ainda, no recorte 2 (cena 2), percebe-se a formação do pré-construído, da repetição vertical, que por sua vez, produz efeitos de memória que nem sempre representam o sentido do enunciado, mas constitui-se na reprodução do discurso do outro, num efeito de espelhamento e reproduz discursos a partir de um já-dito, como se fosse a origem do dizer (COURTINE, 1999). Posto isso, percebe-se que a paráfrase em Vale tudo, entendido como o retorno ao "mesmo", espaço do dizer, trata-se da possibilidade do recorte 1/cena 1 que é retomado, por meio da memória/interdiscurso. Já a polissemia em Pega Pega é compreendida como uma ruptura dos processos de significação, um deslocamento dos sentidos (ORLANDI, 2013), daí, evidenciase, então, Vale Tudo em Pega Pega.

Assim, no recorte 2, o piloto já marca esse lugar polissêmico do diferente, ao enunciar: “- aborta a decolagem”, pois esse novo efeito de sentido, aqui mobilizado, já marca as novas condições de produção do discurso de justiça trazido pela inovação da novela Pega Pega, pois na novela Vale Tudo, o ritual da cena se mostra como se não houvesse falhas (o piloto liga a aeronave e decola tranquilamente). Outro ponto interessante que mostra os modos através dos quais os efeitos de paráfrase e de polissemia se estabelecem entre memória (Vale Tudo) e ruptura (Pega Pega), está na fala do personagem Athaíde, ao enunciar: - "parar, que é isso? Toca esse negócio, toca esse negócioooo". Aqui, é possível observar que o personagem insiste no prevalecimento de uma memória cristalizada de impunidade, trazida pela novela Vale Tudo, contudo, os sentidos sempre estão à deriva, conforme afirma Pêcheux (1990), ao afirmar que todo enunciado é, pois, suscetível de se tornar outro. Desse modo, o outro (Estado punitivo) é trazido para compor o fio discursivo da atualidade.

Em vista disso, pelo viés da $\mathrm{AD}$, o enunciado produzido pelo delegado: - "Athaíde, você está preso por tentativa de fuga, você, Lígia, pelo atentado que matou Mirela Ribeiro", e, também pelo personagem Antônia: “agora, a história é outra, você não vai dar uma banana para o Brasil", marcam na superfície textual o modo como a memória discursiva se apresenta nesses dois recortes discursivos analisados aqui, bem como o efeito de completude que a novela Pega Pega (2017) exerceu sobre a novela Vale Tudo (1988), ao se posicionar como o complemento de algo que faltava na antiga trama telenovelística e, que, agora, foi trazida sob a presença do novo (Pega Pega).

Portanto, do exposto, nessas situações, os discursos, conforme Pêcheux e Fuchs (1993) estão imbricados com as formações ideológicas (FI) e discursivas (FD), associadas, sempre, a 
uma memória social, quer dizer, toda formulação possui, em seu “domínio associado" outras formulações que ela repete, refuta, transforma, nega, enfim, em relação às quais se produzem certos efeitos de memória específicos.

Tais efeitos podem produzir a lembrança ou o esquecimento, a reiteração ou o silenciamento de enunciados. Assim, “o que vem pela história, vem pela memória, pelas filiações de sentidos constituídos em outros dizeres, em muitas outras vozes, no jogo da língua que vai se historicizando aqui e ali" (ORLANDI, 2001, p. 32). E como efeito de materialidade, tem-se o repetível, o que foi dito outras vezes, em momentos clássicos na telenovela.

Logo, o acontecimento visto no capítulo, aponta para os movimentos parafrásticos e polissêmicos, em que via memória discursiva e do interdiscurso, na cena, o vilão das sete, nessa movencia de "reviver" e "refazer" "aquele vilão corrupto" daquela, então, "novela das oito" dá visibilidade aos movimentos de ontem (matriz) e hoje (fonte) de sentidos que se fundam sob essas diferentes conjunturas, reverberando "o mesmo" que se transforma e significa "diferente".

\section{CONSIDERAÇÕES FINAIS}

A telenovela brasileira é um gênero audiovisual e tem sido objeto de pesquisas onde vários autores têm buscado estudar e entendê-la, uma vez que é vista a partir de diversas perspectivas: como um sistema de narrativa central da contemporaneidade (BUONNANO, 2004); gênero com maior possibilidade de exportação (MAZZIOTTI, 2004); narrativa popular sobre a nação (LOPES, 2004); ofício de imaginar para a nação (MARTÍN-BARBERO, 2004) e uma forma de brasilianização da cultura (STRAUBHAAR, 2004).

Nesse contexto, estão circunscritas Pega Pega (2017), telenovela que tendo como enredo uma comédia romântica policial, soube como abordar a questão romanesca com nuances de riso, mas, sobremaneira, destacou que o sujeito será/deverá ser punido por suas transgressões, ainda que se arrependa de seus atos e alcance o perdão. Já Vale Tudo (1988), por outro lado, mostrou que existem aqueles que matam, roubam, cometem tantos outros delitos e, mesmo assim, não se arrependem disso e nem são punidos, “a novela uniu um excelente folhetim com crítica social ao país a partir de uma pergunta comum aos brasileiros: "vale a pena ser honesto no Brasil de hoje?”. O ano era 1988, mas a questão nunca deixou de ser atual” (XAVIER, 2012, s/p). 
A partir das postulações materializadas, nesse artigo, evidenciou-se que há uma intelecção com os recortes/cenas extraídas da mídia, possibilitando uma "repetição" entre telenovelas. No sentido de que, tanto no recorte 1(cena 1), como no recorte 2(cena 2), estão os dois vilões corruptos, sendo que, um "das oito" e outro "das sete", mas, ambos interpretados pelo mesmo ator, Reginaldo Faria, em décadas distintas, respectivamente, (1988/1989) e (2017/2018). Pode-se, então, notar, entre os muitos efeitos de sentido, que para a construção da última, a autora de Pega Pega, (re)elabora e (re)constrói seu texto/imagem/cenas, baseada no que se pode chamar de "discurso fundador", aquele que "primeiro" forneceu subsídios para a (re)construção, repetição e transformação de um "puro já dito", uma vez que no campo da literatura telenovelística, na dramaturgia tudo pode acontecer.

As cenas são parecidas esteticamente, isto é, os personagens são dois grandes vilões corruptos que aprontam ao longo de toda a trama e, no final, tentam escapar ilesos de suas falcatruas. Entretanto, em Vale tudo, Marco Aurélio no recorte 1(cena 1), escapa e foge do Brasil. Não sem antes, debochadamente, olhar para a câmera e mandar uma banana para $o$ país, ao som de "Brasil", interpretada por Gal Costa. Evidenciando/sendo uma das expressões poucas vezes, pronunciada, mas, na grande maioria, acompanhada, apenas, do gesto cheio de firmeza para outro sujeito, que, em seus muitos efeitos de sentido, pode significar: raiva, vingança, desabafo, desrespeito ou uma ofensa. Nesse caso, à nação, aos brasileiros, reinterando aquele "velho discurso", sempre muito presente e atual do "jeitinho brasileiro", onde determinados políticos e/ou empresários, aprontam quase sempre e, no final das contas, "tudo acaba em pizza”, porque o Brasil seria/é o “país da impunidade”.

Como a novela das oito, a trama das sete, também levantou questões sobre ética, crimes, no entanto, possibilitou em seu último capítulo, uma punição/correção que só aconteceu trinta anos depois, para um momento ontológico, histórico e bastante polêmico da/na teledramaturgia, ao não punir os personagens de má índole, o mau caráter que aprontou a novela inteira e depois de aplicar um grande golpe financeiro, foge junto a sua mulher assassina.

O final inusitado, que fez alusão à clássica passagem em Vale Tudo, mostra o desfecho do corrupto, a cara do Brasil atual, segundo o ator Reginaldo Faria (a sequência fez uma homenagem ao intérprete dos dois vilões na TV) (GSHOW, 2018). Desse modo, gerando, então, um "efeito de evidência, correção", pois os tempos são outros, possibilitando um desfecho de punição para o corrupto e a assassina. O cenário de 30 anos depois do que foi denunciado em Vale Tudo, "não é motivo de alegria para ninguém” (GSHOW, 2018, s/p). Entretanto, em alguns casos, é claro, sabe-se que a justiça tarda, falha, mas também, pode não falhar, nem tardar e, 
pelo menos, para satisfação de noveleiros do Brasil, na ficção, houve a correção para a impunidade, com prisões.

A partir das análises, foi possível constatar que ao retomar-se outro dizer, evidencia-se um efeito de reinterpretação, que se modifica, faz da memória e do interdiscurso o novo que é, também, passível de mudanças (SILVA et al, 2017). Portanto, através da relação entre o mesmo (paráfrase) e o diferente (polissemia), forças que atuam de forma contínua no dizer, com tal intensidade, que há a (re)elaboração de outros discursos que são (re)construídos.

"E é nesse jogo que os sujeitos, os sentidos se movimentam, fazem seus percursos e (se)significam" (GOMES, 2006, p. 03). Portanto, certamente, a literatura telenovelística se encontra presente na sociedade através das interações, transmissões de valores, padrões de comportamentos, socializando muitas gerações e, sobretudo, disponibilizando representações históricas, sociais, culturais, ideológicas e discursivas. Estas narrativas, de acordo com Silva (2013, p. 13) “fornecem um cenário simbólico de imagens, discursos, trilhas sonoras com suas tramas extremamente ambivalentes". Desse modo, interpelando os sujeitos/telespectadores e convidando-os a identificarem-se com suas histórias, valores e comportamentos sociais.

\section{REFERÊNCIAS}

ALTHUSSER, Louis. Aparelhos ideológicos de estado: nota sobre os aparelhos ideológicos do Estado (AIE). Rio de Janeiro, Edições Graal, p. 92-99, 1985.

ALTHUSSER, Louis. Freud e Lacan, Marx e Freud: introdução crítica-histórica. Rio de Janeiro: Edições Graal, 1991.

AMOROSO, Patrícia; MONTUORI, Carla. Bebel e Olavo - idolatrados "vilões" e "mocinhos" das oito: uma análise intertextual da novela Paraíso Tropical. Disponível em: https://www.revistas.usp.br/caligrama/article/view/68133. Acesso em: 23 dez. 2017.

BALOGH, Anna Maria. O discurso Ficcional na TV: Sedução e Sonho em Doses Homeopáticas. São Paulo: Editora da Universidade de São Paulo, 2002.

BORGES, Águida Aparecida da Cruz. No detalhe do traço: ritos, cores e resistência. In: ZOPPI-FONTANA, Mônica G.; FERRARI, Ana Josefina. (orgs.). Mulheres em discurso: identificação de gênero e práticas de resistência, Vol. 2, Campinas, São Paulo: Pontes Editores, p. 121-134, 2017.

BORELLI, Sílvia Helena Simões. (Org). Gêneros ficcionais, produção e cotidiano na cultura popular de massa. SP. INTERCOM/CNPq. 1994.

BUONNANO, Milly. Além da proximidade cultural: não contra a identidade, mas a favor da alteridade. Para uma nova teoria crítica dos fluxos televisivos interacionais. In. LOPES, Maria Immacolata Vassallo de. (org.). Telenovela. Internacionalização e Interculturalidade. São Paulo, Edições Loyola: 2004. 
CAZARIN, Ercília Ana. Interlocução discursiva: a afirmação funcionando como negação. In: ERNST-PEREIRA, Aracy; FUNCK, Suzana Bornéo. (orgs.). A leitura e a escrita como práticas discursivas. Pelotas: Educat, p. 137-144, 2001.

CHUMBOGORDO. Cuidado com a banana. Disponível em:

<http://www.chumbogordo.com.br/5986-cuidado-com-banana/>. Acesso em: 10 jan. 2020.

COURTINE. Jean Jacks. O chapéu de Clémentis. Observações sobre a memória e o esquecimento na enunciação do discurso político. In: INDURSKY, F.; FERREIRA, M. C. L. (Orgs.). Os múltiplos territórios da Análise do Discurso. Porto Alegre: Editora SagraLuzzato, 1999, p. 15-22.

ÉPOCA. Estreia de pega pega quebra recorde de audiência às $7 \mathbf{h}$. Disponível em: <https://epoca.globo.com/sociedade/bruno-astuto/noticia/2017/06/estreia-de-pega-pega-quebraindice-deaudiencia-7.html>. Acesso em: 10 jan. 2020.

EXTRA. Punido em 'Pega pega', Reginaldo Faria revive cena de 'Vale tudo' e dispara: 'Nossos políticos é que são os bananas'. Disponível em:< https://extra.globo.com/tv-elazer/punido-em-pega-pega-reginaldo-faria-revive-cena-de-vale-tudo-dispara-nossospoliticos-que-sao-os-bananas-22240892.html > . Acesso em: 31 mai. 2018.

GOMES, Antônio Marcos Tosoli. O desafio da análise de discurso: os dispositivos analíticos na construção de estudos qualitativos. R Enferm UERJ, Rio de Janeiro, 2006 out/dez; 14(4):620-6. Disponível em: 〈http://www.facenf.uerj.br/v14n4/v14n4a20.pdf> Acesso em: 28 mai. 2018.

GSHOW. A polícia intercepta o avião de Athaíde e Lígia. Disponível em: <http://gshow.globo.com/novelas/pega-pega/capitulo/2018/01/08/\#video-6407430> Acesso em: 28 mai. 2018.

GSHOW. Fuga de Athaíde tem citação à cena de 'Vale Tudo'; confira os bastidores. Disponível em: <https://gshow.globo.com/novelas/pega-pega/noticia/fuga-de-athaide-temcitacao-a-cena-de-vale-tudo-confira-os-bastidores.ghtml> Acesso em: 31 mai. 2018.

GSHOW. 'Pega Pega': conheça o elenco da nova novela das 7. Disponível em: <https://gshow.globo.com/tv/noticia/pega-pega-conheca-o-elenco-da-nova-novela-das7.ghtml> Acesso em: 28 mai. 2018.

HAROCHE, Claudine. Fazer, dizer, querer, dizer. São Paulo: Hucitec, p. 178, 1992.

HOLANDA, Francisco Thiê da Conceição. "Sem querer querendo": análise do programa chaves e sua permanência por 40 anos em exibição. Centro de Ensino Superior do Ceará Faculdade Cearense Curso de Publicidade e Propaganda (Monografia em Publicidade e Propaganda). Fortaleza, 2014. Disponível em:

<https://www.faculdadescearenses.edu.br/biblioteca/TCC/PUB/SEM\%20QUERER\%20QUE RENDO/pdf $>$. Acesso em: 28 abr. 2017.

LAGAZZI, Suzy. Linha de Passe: a materialidade significante em análise. RUA [online] Revista do Laboratório de Estudos Urbanos do Núcleo de Desenvolvimento da Criatividade. Disponível em: <http://www.labeurb.unicamp.br/rua/>, n. 16, v. 2, 2010. Acesso em: 12 janeiro 2019.

LEANDRO FERREIRA, Maria Cristina. Linguagem, ideologia e psicanálise. Estudos da Língua(gem), Vitória da Conquista, v. 01, p. 69-75, Jun., 2005. Disponível em: 
<http://estudosdalinguagem.cpelin.org/index.php/estudosdalinguagem/article/viewFile/10/16> Acesso em: 24 jul. 2014.

LIMA, Solange Martins Couceiro. et al. A telenovela e o Brasil: Relatos de uma experiência acadêmica. Revista Brasileira de Ciências da Comunicação, vol. XXIII, nº 1, 2000.

MALISKA, Maurício Eugênio. A voz: um corpo que não engana. In: FLORES, G. G. B.; GALLO, Solange Maria Lêda; LAGAZZI, Suzy. (orgs). Análise do discurso em rede: cultura e mídia. Vol. 3, Campinas, São Paulo: Pontes Ed., p. 50-70, 2017.

MARTÍN-BARBERO, Jesús. Televisión y Melodrama. Géneros ylecturas de la telenovela en Colombia. Bogotá, Colombia: Tercer mundo editores, 1992.

MARTÍN-BARBERO, Jesús. Dos meios às mediações: comunicação, cultura e hegemonia. 2.ed. Rio de Janeiro: Editora UFRJ, 2003.

MAZZIOTTI, Nora. A força da emoção. A telenovela: negócios, audiências, histórias. In. LOPES, Maria Immacolata Vassallo de. (org.). Telenovela. Internacionalização e Interculturalidade. São Paulo: Edições Loyola, 2004.

MEMÓRIA GLOBO. Uma banana para o brasil. Tramas paralelas. Disponível em: $<$ http://memoriaglobo.globo.com/programas/entretenimento/novelas/vale-tudo/uma-bananapara-o-brasil.htm> Acesso em: 28 mai. 2018.

MEMÓRIA GLOBO. Vale tudo. Trama Principal. Disponível em: $<$ http://memoriaglobo.globo.com/programas/entretenimento/novelas/vale-tudo/tramaprincipal.htm> Acesso em: 28 mai. 2018.

MOISÉS, Massaud. A criação literária. Editora Cultrix, São Paulo, 1985, p. 55.

NA TELINHA. Em desfecho, "Pega Pega" terá referência a "Vale Tudo" em cena de helicóptero "Pega Pega". Disponível em:

$<$ https://natelinha.uol.com.br/novelas/2017/12/28/em-desfecho-pega-pega-tera-referencia-avale-tudo-em-cena-de-helicoptero-113146.php> Acesso em: 31 mai. 2018.

NOTÍCIAS DA TV. Pega Pega corrige impunidade de Vale Tudo com prisão no último capítulo. Disponível em: <http://noticiasdatv.uol.com.br/noticia/novelas/pega-pega-corrigeimpunidade-de-vale-tudo-com-prisao-no-ultimo-capitulo-18410> Acesso em: 28 mai. 2018.

ORLANDI, Eni. Punicelli. Discurso e Texto: formulação e circulação de sentidos. Campinas/SP: Pontes, 2001.

ORLANDI, Eni. Punicelli. As formas do silêncio: no movimento dos sentidos. Campinas SP: Editora da UNICAMP, 2007.

ORLANDI, Eni. Punicelli. A linguagem e seu funcionamento: as formas do discurso. Campinas: Pontes, 2011.

ORLANDI, Eni. Punicelli. Análise de discurso: princípios e procedimentos. 10.ed. Campinas, SP: Pontes Editores, 2013.

ORLANDI, Eni. Punicelli. Análise de discurso. In: LAGAZZI, Suzy; ORLANDI, Eni Punicelli. (orgs.). Discurso e textualidade, 3 Ed, Campinas, São Paulo: Pontes Editores, p. 13-76, 2015.

ORTIZ, Renato. et al. Telenovela: história e produção. 2a . ed. São Paulo: Brasiliense, 1991. 
PÊCHEUX, Michel. Rôle de La mémoire. In: MALDIDIER, Denise. (Org.). Histoire et Linguistique. Paris: Editions de La Maison des Sciences de 1’Homme, 1984.

PÊCHEUX, Michel. Papel da Memória. In: ACHARD, Pierre [et al.]. Papel da Memória. Campinas, SP: Pontes Editores, 2010, p.49-57.

PÊCHEUX, Michel. Semântica e discurso: uma crítica à afirmação do óbvio. 3.ed. Campinas, SP: Editora da Unicamp, [1975] 1997, p. 159-185.

PÊCHEUX, Michel. Por uma análise automática do discurso. Campinas: UNICAMP, [1969]1993.

PÊCHEUX, Michel. O discurso: estrutura ou acontecimento. Tradução de Eni Orlandi, Campinas, SP: Pontes, 1990.

SILVA, Rodrigo de Santana. Et al. Entre paráfrase e polissemia: a movência dos sentidos e dos sujeitos em "saímos do Facebook". Entrepalavras, Fortaleza, v. 7, p. 229-242, ago./dez. 2017. Disponível em:

<http://www.entrepalavras.ufc.br/revista/index.php/Revista/article/view/764> Acesso em: 28 mai. 2018.

SILVA, Lourdes. Melodrama e telenovela: dimensões históricas de um gênero/formato. $9^{\circ}$ Encontro Nacional de História da Mídia, 2013. UFOP, Ouro Preto/Minas Gerais. Disponível em: <http://www.ufrgs.br/alcar/encontros-nacionais-1/9o-encontro-2013/artigos/gt-historiada-midia-audiovisual-e-visual/melodrama-e-telenovela-dimensoes-historica-de-um-generoformato> Acesso em: 23 dez. 2017.

SOARES, Alexandre Ferrari. Sem corpo, sem língua, num entrelugar: sobre os sujeitos transexuais na mídia. In: FLORES, Giovanna. G. Benedetto. et al (orgs.). Análise do discurso em rede: cultura e mídia. Vol. 3, Campinas, São Paulo: Pontes Ed., p. 35, 2017.

STRAUBHAAR, Joseph. As múltiplas proximidades das telenovelas e das audiências. In. LOPES, M. I. V. (org.). Telenovela. Internacionalização e Interculturalidade. São Paulo: Edições Loyola, 2004.

TERRA. Como não amar "vale tudo"? 10 motivos para curtir a reprise desse clássico que faz 30 anos. Por Duh Secco - 16 de maio de 2018 - 18:00. Disponível em: $<$ https://rd1.com.br/como-nao-amar-vale-tudo-10-motivos-para-curtir-a-reprise-desseclassico-que-faz-30-anos/> Acesso em: 10 jan. 2020.

TERRA. "Pega Pega" corrige impunidade de "Vale Tudo" e mostra que a justiça tarda, mas não falha. Disponível em: <https://rd1.com.br/pega-pega-corrige-impunidade-de-valetudo-e-mostra-que-a-justica-tarda-mas-nao-falha/> Acesso em: 28 mai. 2018.

THOMASSEAU, Jean-Marie. O Melodrama. São Paulo: Perspectiva, 2005.

XAVIER, Nilson. Novela "Vale Tudo" completa 24 anos de sua estreia. Disponível em: $<$ https://nilsonxavier.blogosfera.uol.com.br/2012/05/16/novela-vale-tudo-completa-24-anosde-sua-estreia/> Acesso em: 28 mai. 2018. 